\title{
Real-Time Pcr for Identification of Aspergillus Niger
}

\author{
Aline Morgan von Hertwig (I), Maristela da Silva do Nascimento (I), \\ Maria Helena Pelegrinelli Fungaro (II), Marta Hiromi Taniwaki (I) \\ (I) ITAL - INSTITUTO DE TECNOLOGIA DE ALIMENTOS (Av. Brasil, 2880 - CEP 130.70-178 \\ Campinas-SP, Brazil), (II) UEL - Universidade Estadual de Londrina (Rodovia Celso Garcia \\ Cid, Km 380 - Campus Universitário, CEP 86057-970, Londrina)
}

\section{Resumo}

Some species of the genus Aspergillus section Nigri deserve attention as they are able to produce ochratoxin A and fumonisin B2, mycotoxins of a nephrotoxic character, immunosuppressors and cytotoxic activity, along with carcinogenic and teratogenic potential for some animals. The taxonomy of section Nigri still generates some controversy, probably because for many years the classification has been based only on morphological criteria and in some cases it is not possible to differentiate among species. The aim of this study was to identify Aspergillus niger by the molecular method real-time PCR. Sixty samples of Aspergillus section Nigri isolated from Brazil nuts, coffee, cocoa and dried fruits were selected. For DNA extraction, the isolates were grown on malt extract for two days at $25^{\circ} \mathrm{C}$ and then PowerLyzerTM PowerSoil DNA Isolation (Mobio) kit was used for DNA extraction following the manufacturer's recommendations. Amplification reactions were performed using primers and specific probes for Aspergillus niger using Applied Biosystems @ 7500 Real-Time PCR. The results were analyzed using the device software. Twenty-seven of the sixty isolates were amplified and therefore identified as Aspergillus niger. Twenty-nine strains had been previously identified by other molecular techniques (sequencing or RAPD) showing that eight isolates belonged to the Aspergillus niger species, ten to Aspergillus carbonarius and eleven to Aspergillus tubingensis species. All eight isolates previously identified as Aspergillus niger showed amplification with Real Time PCR. In the case of strains belonging to the species Aspergillus 
carbonarius, there was no amplification for any of the ten representative analyzed, confirming the results obtained from other techniques. Eleven Aspergillus tubingensis strains were analyzed with one isolate being amplified. The amplified DNA should be sequenced to confirm the robustness of the primer used for identification of Aspergillus niger. The results show that real Time PCR is a promising technique for the identification of Aspergillus niger, being a quick, easy, discriminatory tool.

Palavras-Chave: Fungi, Ochratoxin A, PCR Agência de Fomento: FAPESP 